\title{
Clinical outcome of the late preterm infants
}

\section{Lutfun Nahar Begum, Farzana Ahmed, Kulsum Haq and Lima Lisa Mallick}

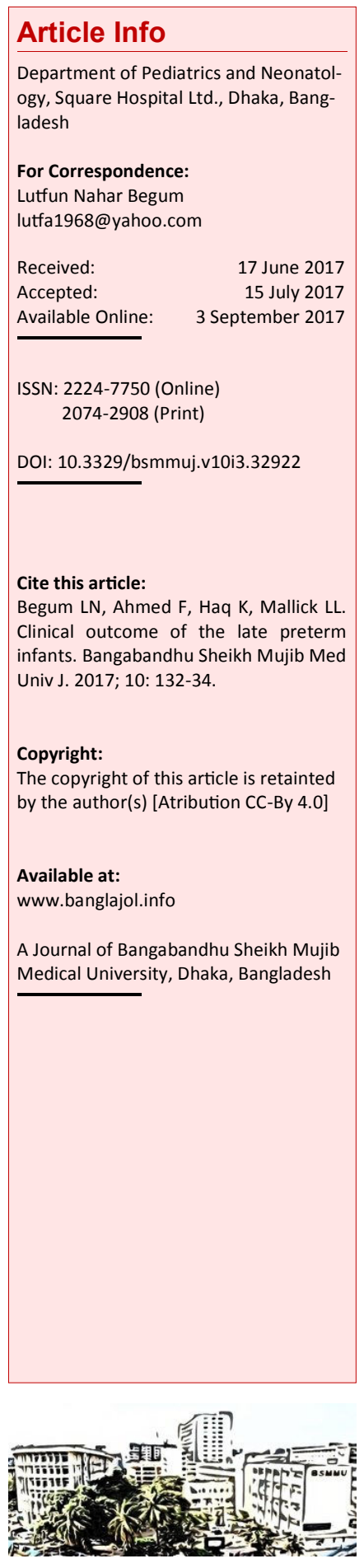

\section{Abstract}

The aim of this retrospective study was to evaluate the short-term clinical outcome of late preterm babies (34-36 week) in a tertiary level hospital from January 2013 to December 2014. A total of 3,749 babies were delivered during this period of which 513 were late preterm. Among the late preterm babies, 481 babies were delivered by cesarean section. Admission to the neonatal intensive care unit after birth was needed in case of 66 babies. Higher incidences of complication like jaundice $(14.4 \%)$, sepsis $(6.2 \%)$, respiratory distress syndrome $(2.9 \%)$, transient tachypnea $(2.3 \%)$ and others were found in comparison to control term babies. Ventilation was required in 11 cases. Late preterm mortality was $1.4 \%$. In conclusion, late prematurity is associated with significant neonatal morbidity and mortality.

\section{Introduction}

Late preterm infants are premature newborns born between 34 to 36 weeks of gestational age.1 Late preterm babies have more chance of jaundice, respiratory problem, sepsis, in comparison of term babies. $2-5$ These babies normally kept in the nursery with the mother. But they can develop major neonatal complications that need admission in neonatal intensive care unit. $\underline{6}$, 7 Late preterm babies are increasing due to termination of high-risk pregnancies. Data mostly are found from the developed countries. The outcome of the late preterm babies depends on racial and demographic factors. It also varies in different hospitals of the same country. There is very few data available on the problems of late preterm babies in the developing countries. The obstetric as well as newborn scenarios of the developing countries are different from the developed countries. This study focuses on the short-term morbidities and mortalities of late preterm babies in our hospital.

\section{Materials and Methods}

This retrospective study was done at the neonatal intensive care unit and nursery of Square Hospital Ltd from January 2013 to December 2014. Babies delivered between 34 to 36 weeks were included as cases. Babies born above 37 weeks gestation during the study period were taken as controls. The data were recorded like gestational age, mode of delivery, sex, birth weight, admission at neonatal intensive care unit, death and neonatal morbidities.
The gestational age was determined by last menstrual period and first-trimester ultrasound scan if available and the New Ballards score. The babies who developed respiratory distress were shifted to the neonatal intensive care unit (NICU). Late preterm morbidities were compared with term babies who were admitted at neonatal intensive care unit. Neonatal morbidities like respiratory distress syndrome, transient tachypnea, sepsis, jaundice and perinatal asphyxia were noted. Data on the respiratory support such as nasal continuous positive airways pressure, mechanical ventilation were collected. The need for surfactant administration was also recorded. Overall mortality was calculated.

Demographic characteristics of the two groups, late preterm and term babies were assessed by descriptive analysis. Chi-square test was used for comparison of morbidity and mortality of two groups. Statistical significance was noted at $\mathrm{p}<0.05$.

\section{Results}

During the study period, total 3,749 babies were delivered. Out of them $513(13.7 \%)$ were the late preterm babies and 3,236 babies were the term (Table I). Out of 513 late preterm babies, 261 were females (50.9\%). 481 (93.8\%) late preterm babies were born by lower segment cesarean section and 32 babies $6.2 \%$ were born through vaginal route. $66(12.9 \%)$ late preterm and 36 (1.1\%) term babies required NICU admission just after birth. 
Table I

\begin{tabular}{l|cc|}
\multicolumn{3}{|c|}{ Characteristics of the study population } \\
\hline \multicolumn{2}{|c|}{ Percentage } \\
\hline Parameters & $\begin{array}{c}\text { Late preterm } \\
(\mathrm{n}=513)\end{array}$ & $\begin{array}{c}\text { Term } \\
(\mathrm{n}=3,236)\end{array}$ \\
Mode of delivery & & \\
Cesarean section & 93.8 & 87.5 \\
Normal vaginal & 6.2 & 12.5 \\
Sex & & \\
Male & 49.1 & 50.6 \\
Female & 50.9 & 49.4 \\
Complication & & \\
Jaundice & 14.4 & 4.8 \\
Sepsis & 6.2 & 0.2 \\
Respiratory distress syndrome & 2.9 & 0.0 \\
Transient tachypnea of the new- & 2.3 & 0.2 \\
born & & \\
Ventilation & 2.1 & 0.1 \\
Continuous positive airway & 2.1 & 0.0 \\
pressure & & 0.0 \\
Surfactant & 0.5 & 0.2 \\
Perinatal asphyxia & 1.2 & \\
Death & 1.4 & 0.0 \\
\hline
\end{tabular}

Seventy-four late preterm babies and 155 term babies had jaundice required phototherapy (14.4 vs $4.8 \%)$. Respiratory distress syndrome developed in 15 late preterm and 1 term baby ( 2.9 vs $0.0 \%$ ), sepsis in 32 in late preterm and 7 in term babies (6.2 vs 0.2 \%). $12(2.3 \%)$ late preterm and $5(0.2 \%)$ term babies developed transient tachypnea, $6(1.2 \%)$ late preterm and $8(0.2 \%)$ term babies developed perinatal asphyxia.

Eleven $(2.1 \%)$ late preterm babies required ventilation, 2 term babies $(0.1 \%)$ required ventilation, 11 $(2.1 \%)$ late preterm required continuous positive airway pressure, $1(0.0 \%)$ term baby required continuous positive airway pressure. 3 late preterm babies $(0.5 \%)$ required surfactant. 506 late preterm babies $(98.6 \%)$ survived and 7 (1.4\%) late preterm babies died. All term babies were discharged from NICU.

\section{Discussion}

In our study, short-term morbidities and mortality of late preterm babies were compared with the term babies, who were admitted at NICU.

In our study, $513(13.7 \%)$ babies were the late preterm and 3,236 (86.3\%) were the term. Among them, $66(12.9 \%)$ late preterm and $36(1.1 \%)$ term babies were admitted to the NICU just after birth.
There is increased morbidities and mortality in the late preterm babies in comparison to term babies. The most common complications in late preterm babies are jaundice $(14.4 \%)$, sepsis $(6.2 \%)$, respiratory distress syndrome $(2.9 \%)$, transient tachypnea $(2.3 \%)$. The mortality rate was $1.4 \%$. The study also showed late preterm infants have 5.5 times higherrisk for overall morbidity due to any cause relative to term infants. .8

There was nearly equal sex distribution, similar to another study.2 In our study, cesarean section was high in late preterm babies, as well as also in term babies. Because a significant portion of high-risk mothers were delivered at our tertiary care center. We could not get enough information regarding induction of labor and indications of delivery. The study showed that elective cesarean section had higher mortality and respiratory morbidity in both late preterm and early term babies. 9 So, the optimal outcome of mother and babies should be the major consideration in the decision for the time of delivery. For most of the low-risk uncomplicated singleton delivery, optimal outcomes are usually achieved if the pregnancy continues to full-term.

In our study, the rate of NICU care admission and the need of respiratory support in late preterm infants were high in comparison to term infants. Respiratory morbidity is nearly 14 -fold higher in late preterm when compared with term infants.. In the present study, respiratory distress syndrome was seen in 15 late preterm and 1 in term infants, 12 late preterm and 5 term babies developed transient tachypnea. So, respiratory morbidity in late preterm was $6.4 \%$ and in term infants it was $0.4 \%$, which revealed a similar picture. Marvin et al. study also showed that late preterm babies developed respiratory problems nearly $30 \%$ in comparison to term babies. 10 A study showed that all types of respiratory morbidity as well as the need of respiratory support and adjunctive therapy decreased significantly with gestational age until 39 weeks. $\underline{3}$

Neonatal hyperbilirubinemia requiring phototherapy was high in the late preterm babies as compared to term babies ( 28.7 vs $5 \%$ ) because of developmental immaturity in the liver and feeding difficulties. 2 In another study, 54\% late preterm babies developed jaundice that differed from the term infants (37.9\%).9 In our study, among 3,236 babies, $155(4.8 \%)$ term babies and among 513 late preterm babies, 74 (14.4\%) late preterm babies got phototherapy for jaundice.

The late preterm has more chance of sepsis than term baby due to poor immunity. In our study, 32 (6.2\%) late preterm babies developed sepsis, whereas $7(0.2 \%)$ term babies developed sepsis. Another study also showed the similar result. 11

Studies showed that late preterm infants are at high -risk of death during the neonatal period, particu- 
larly in the first few days of life.12 The neonatal mortality rate in late preterm was 7.4 -fold higher than in term infants. $\underline{13,14}$ In our study, 7 (1.4\%) late preterm babies died and all term babies survived.

The late preterm group is associated with significant increased use of intensive care, longer stay of hospitalization, and concomitant increased hospital charges. They have more subtle neurodevelopmental issues such as inferior academic performances or behavioral problems and increased the risk of cerebral palsy as compared to term. We could not measure the human and economic impacts of prematurity and the long-term morbidities. We could not determine the etiology of preterm births especially iatrogenic late prematurity.

\section{Conclusion}

Late prematurity is associated with significant neonatal morbidity and mortality in comparison with term babies. They are most vulnerable population and need proper attention from the beginning of birth.

\section{References}

1. Raju TN, Higgins RD, Stark AR, Leveno KJ. Optimizing care and outcome for late preterm (near -term) infants: A summary of the workshop sponsored by the National Institute of Child Health and Human Development. Pediatrics 2006; 118: 1207-14.

2. Sahana, Adarsh E, Sunil, Rajanish, Sreekrishna. Short-term outcome of late preterms. Int J Med Appl Sci. 2014; 3: 205-11.

3. Natile M, Ventura ML, Colombo M, Bernasconi D, Locatelli A, Plevani c, Valsecchi M G. Shortterm respiratory outcomes in late preterm infants. Italian J Pediatr. 2014: 40-52.

4. Gouyon JB, Iacobelli S, Ferdynus C, Bonsante F. Neonatal problems of late and moderate preterm infants. Semin Fetal Neonatal Med. 2012; 17: 146-52.

5. Ramachandrappa A, Rosenber ES, Wagoner S, Jain L. Morbidity and mortality in late preterm infants with severe hypoxic respiratory failure on extracorporeal membrane oxygenation. J Pediatr. 2011; 159: 192-98.

6. McIntire DD, Leveno KJ. Neonatal mortality and morbidity rates in late preterm births compared with births at term. Obstet Gynecol. 2008; 111: 3541.

7. Tomashek KM, Shapiro-Mendoza CK, Davidoff MJ, Petrini JR. Differences in mortality between late preterm and term singleton infants in the United States, 1995-2002. J Pediatr. 2007; 151: 450-56.

8. Jaiswal A, Murki S, Gaddam P, Reddy A. Early neonatal morbidities in late preterm infants. Indian Pediatr. 2011; 48: 607-11.

9. De Luca R, Boulvain M, Irion O, Berner M, Pfister RE. Incidence of early neonatal mortality and morbidity after late preterm and term cesarean delivery. Pediatrics 2009; 123: e1064-71.

10. Marvin L, Wang, David J. Fleming MP, Catlin EA Clinical outcomes of near-term infants. Pediatrics 2004; 114: 372.

11. Femitha P, Vishnubhat B. Early neonatal outcome of late preterms. Indian J Paediatr. 2012; 79: 1019 24.

12. Kramer MS, Demissie K, Yang H, Platt RW, Sauvé $\mathrm{R}$, Liston R. The contribution of mild and moderate preterm birth to infant mortality, fetal and infant health study group of the canadian perinatal surveillance system. JAMA. 2000; 284: 843-49.

13. Teune MJ, Bakhuizen S, Gyamfi Bannerman $C$ Opmeer BC, Van Kaam AH, Van Wassenaer AG, Morris JM, Mol BW. A systematic review of severe morbidity in infants born late-preterm. Am J Obstet Gynecol. 2011; 205: 374.

14. Khashu M, Narayanan M, Bhargava S, Osiovich H. Perinatal outcomes associated with preterm birth at 33 to 36 weeks' gestation: A population-based cohort study. Pediatrics 2009; 123: 109-13. 